\title{
Matching when the number of response alternatives is large*
}

\author{
H. L. MILLER, JR.† and DONALD H. LOVELAND \\ Hanard University, Cambridge, Massachuset ts 02138
}

\begin{abstract}
Pigeons could choose between five concurrently available response keys, each associated with a different variable-interval schedule of reinforcement. A 2-sec changeover delay was also in effect on each key. In almost all cases, the relative number of responses to a key and the relative time spent at it were nearly equivalent to the relative number of reinforcements it produced. In addition, matching was observed between the relative number of reinforcements at a key and the relative number of changeovers to it.
\end{abstract}

Although Herrnstein's (1970) formulation of the matching principle provides for the general case of several response alternatives, in nearly all studies of matching the number of alternatives has been restricted to two. Typically, the experimental situation is one in which Ss choose between a pair of concurrently available variable-interval (VI) schedules of primary reinforcement. When matching appears under such conditions, it can be expressed by the equation

$$
\frac{P_{1}}{P_{1}+P_{2}}=\frac{R_{1}}{R_{1}+R_{2}}
$$

where $P$ signifies the number of responses emitted and $R$ the number of reinforcements obtained. The subscripts denote the respective response alternatives and the reinforcement sources associated with them.

An exception to this now standard situation was provided by Reynolds (1963), who exposed pigeons to a condition in which three response keys were available. His procedure was a variant of that first introduced by Autor (1969) and now commonly termed a concurrent-chains schedule. In Reynolds's experiment, two-member chain schedules were assigned to each of the three keys. The initial members (or links) of the three chains consisted of identical VI schedules. The keys were also illuminated identically. Whenever an interval elapsed on the VI schedule associated with a particular key, the next response on that key produced either of two effects: (1) The color of the key that had just been pecked was changed and the other two keys were darkened and became inoperative, or (2) all three keys were darkened and made inoperative. This latter effect is known as time-out (TO). The probability that the former effect occurred, i.e., that a keypeck produced a change of key color, was different for each key. When pecking in the first link produced a change in key color for one of the keys, a fixed-ratio (FR) schedule went into effect on that key and remained in effect until the

\footnotetext{
*This research was supported by Grant MH-15494-05 from the NIMH to Harvard University. The authors gratefully acknowledge the suggestions of Will Vaughan. Reprints may be obtained from H. L. Miller, Jr., Department of Psychology and Social Relations, Harvard University, Cambridge, Massachusetts 02138.

+National Science Foundation predoctoral fellow.
}

ratio was completed and food delivered. The ratio was the same in all terminal links. Following reinforcement the initial links were reinstated. If responding in the initial links had produced a TO, the animal remained in that condition for $30 \mathrm{sec}$ before the initial links resumed.

Reynolds alternated sessions in which the three-key choice was available with sessions in which one of the keys was covered and the choice was between the remaining pair. In both cases he found equivalence between the relative rates of responding in the initial links and the relative rates of reinforcement in the terminal links. When three keys were available, he expressed the function relating responses and reinforcements as

$$
\frac{P_{1}}{P_{1}+P_{2}+P_{3}}=\frac{R_{1}}{R_{1}+R_{2}+R_{3}}
$$

Given Reynolds's procedure, though, it should be obvious that the following function could also be accurately applied to his results:

$$
\frac{P_{1}}{P_{1}+P_{2}+P_{3}}=\frac{1-X_{1}}{\left(1-X_{1}\right)+\left(1-X_{2}\right)+\left(1-X_{3}\right)}
$$

where $\mathbf{P}$ signifies initial links response rates and $\mathrm{X}$ indicates the relative rate of entry into a terminal link containing the FR schedule. Thus, the quantity $1-X$ represents the relative rate of TO in the terminal links associated with the particular keys denoted by the subscripts. In this view, the animals in Reynolds's experiment distributed their responding in a way that minimized the occurrence of an aversive event-TO.

Reynolds also considered the conditional probabilities of switching to particular keys as a function of the relative rates of reinforcement they produced. That is, given that a peck had occurred to one of the three keys, he calculated the probability that the next peck would be directed to one or the other of the alternative keys. He then plotted these probabilities as a function of the rates of reinforcement obtained on the alternatives. In all cases, linear relationships emerged, but they generally departed from those consistent with matching by exhibiting slopes steeper than that displayed by the 
Table 1

Sums of the Data for Each Subject from the Last Five Sessions of the Five-Key Concurrent Procedure

\begin{tabular}{|c|c|c|c|c|}
\hline Key & Responses & $\begin{array}{l}\text { Time } \\
\text { (Min) }\end{array}$ & $\begin{array}{c}\text { Change- } \\
\text { overs }\end{array}$ & $\begin{array}{l}\text { Reinforce- } \\
\text { ments }\end{array}$ \\
\hline \multicolumn{5}{|c|}{ Bird 258} \\
\hline 1 & 3969 & 31.57 & 363 & 87 \\
\hline 2 & 2151 & 24.54 & 303 & 42 \\
\hline 3 & 1286 & 10.91 & 128 & 29 \\
\hline 4 & 1184 & 12.33 & 136 & 23 \\
\hline 5 & 730 & 6.80 & 80 & 17 \\
\hline Total & 9320 & 86.15 & 1010 & $198^{*}$ \\
\hline \multicolumn{5}{|c|}{ Bird 348} \\
\hline 1 & 5355 & 44.28 & 404 & 107 \\
\hline 2 & 12 & .14 & 12 & 0 \\
\hline 3 & 4613 & 21.11 & 335 & 39 \\
\hline 4 & 3077 & 22.90 & 322 & 33 \\
\hline 5 & 1787 & 22.70 & 415 & 21 \\
\hline Total & 14844 & 111.13 & 1488 & 200 \\
\hline \multicolumn{5}{|c|}{ Bird 261} \\
\hline 1 & 5774 & 59.54 & 408 & 100 \\
\hline 2 & 3053 & 18.31 & 302 & 39 \\
\hline 3 & 1315 & 7.29 & 113 & 25 \\
\hline 4 & 1372 & 7.32 & 96 & 20 \\
\hline 5 & 513 & 4.87 & 63 & 16 \\
\hline Total & 12027 & 97.33 & 982 & 200 \\
\hline \multicolumn{5}{|c|}{ Bird 299} \\
\hline 1 & 4014 & 62.15 & 256 & 97 \\
\hline 2 & 906 & 11.63 & 148 & 40 \\
\hline 3 & 842 & 8.38 & 137 & 25 \\
\hline 4 & 562 & 6.22 & 105 & 20 \\
\hline 5 & 689 & 6.25 & 115 & 18 \\
\hline Total & 7013 & 94.63 & 761 & 200 \\
\hline
\end{tabular}

Note-The amount of time spent on a key excludes the time occupied by reinforcement. A changeover was recorded whenever an animal switched to a key from any of the four other keys. *The five-session total should have been 200. An equipment failure resulted in the termination of one of the sessions after 38 (instead of 40) reinforcements had been delivered.

matching function, i.e., they had slopes greater than 1.0. Reynolds attributed this disparity to behavioral contrast.

Reynolds's analysis in terms of conditional probabilities obscured a more basic datum, namely, the relative frequency of switches to a particular key. One explanation for his failure to include this measure may have been its inapplicability to the situation which involved only two keys. The reason for this should be apparent: The number of switches to either key in a two-key situation or the number of changeovers from one key to another cannot ever differ by more than one. Thus, the relative frequencies of switching are always identical or very close to being identical, regardless of changes in the relative frequencies of reinforcement. However, these constraints no longer operate when the number of alternatives in the choice situation is expanded beyond two. In such situations, it might be possible to find matching between the relative frequency of choice of a particular key, i.e., the relative frequency of switches to it, and the relative frequency of reinforcement on that key.
The present study is the only one thus far reported in which the number of response alternatives in a simple concurrent procedure has been expanded beyond two. Pigeons were exposed to a choice between five response keys, each associated with a different VI schedule. A changeover delay (COD) was in effect for each key. Among the behavioral measures employed in the experiment was the number of times to which individual keys were switched.

\section{METHOD}

\section{Subjects}

Four male White Carneaux pigeons-numbered 258, 261, 299, and 348-were maintained at approximately $80 \%$ of their free-feeding body weights. All had prior experimental histories involving two-key concurrent procedures.

\section{Apparatus}

The experimental chamber was a wooden soundproofed enclosure, the interior of which measured $287 / 8 \mathrm{in} .(74.2 \mathrm{~cm})$ long, $183 / 8 \mathrm{in} .(47.2 \mathrm{~cm})$ wide, and $167 / 8 \mathrm{in}$. (43.2 cm) high. An $18 \cdot 3 / 8$ in. $(47.2 \mathrm{~cm}) \times 167 / 8$ in. $(43.2 \mathrm{~cm})$ aluminum panel containing five response keys and the feeder aperture was placed $11 \mathrm{in} .(28.5 \mathrm{~cm})$ from one end of the chamber. Each key was $3 / 4$ in. $(2 \mathrm{~cm})$ in diam and could be operated by a force of at least $15 \mathrm{~g}(0.147 \mathrm{~N})$. The keys were arrayed horizontally along the panel $95 / 8 \mathrm{in} .(24.5 \mathrm{~cm})$ from the floor. They were referenced according to their position in the array, i.e., Key 1 was on the extreme left, Key 2 was to its right, etc., so that Key 5 was located at the extreme right. The distance from the centers of the endmost keys ( 1 and 5) to the nearest side wall of the chamber was $5 \frac{1 / 4}{4}$ in. $(13.2 \mathrm{~cm})$. The distance between the centers of adjacent keys was 2 in. $(5 \mathrm{~cm})$. Each key was transilluminated by a different colored light. This was achieved by placing colored filters over the $28-\mathrm{V}$ dc lamp located behind each key. Key 1 was blue, Key 2 yellow, Key 3 red, Key 4 green, and Key 5 white. While a key was operative, any response to it produced an audible click from a relay mounted behind the panel. White noise was continuously present during experimental sessions. No houselight was provided.

A rectangular feeder aperture was centered in the panel beneath the keys. It measured $133 / 8 \mathrm{in} .(34.5 \mathrm{~cm}) \times 2$ in. $(5 \mathrm{~cm})$, with its lower edge $31 / 8 \mathrm{in} .(7.8 \mathrm{~cm})$ above the floor. This opening provided access to the food magazine, which extended along the entire length of the aperture. The magazine could be raised and lowered by means of a motorized cam device. The time required to raise the magazine into the position suitable for feeding or to lower it from that position was $0.5 \mathrm{sec}$. The magazine could be illuminated by three 6-W lamps.

Conventional electromechanical programming and recording equipment was located in a separate room.

\section{Procedure}

Ss were initially exposed to a choice involving only Keys 1 and 5. The remaining keys were covered. Reinforcement consisted of a 4-sec operation of the food magazine and was available on a concurrent (conc) VI 5-min schedule. The magazine contained mixed grain. During reinforcement the magazine was illuminated, the keys were darkened and made inoperative, and the VI tape which programmed reinforcement for the alternate key was stopped. A 2-sec COD was also in effect during each session. This prevented reinforcement from occurring on a particular key until at least $2 \mathrm{sec}$ after the $\mathrm{S}$ had switched to that key. Sessions were terminated when a total of 40 reinforcements had been delivered. After each bird had completed 14 sessions, Keys 1 and 5 were covered and Keys 2 and 4 uncovered. Reinforcement was now available on these 
keys. under the same conditions that had previously been in effect. Each animal received 14 sessions with the new pair of keys.

In the final procedure all five keys were available. The programmed schedule of reinforcement was changed to a conc VI $1 \mathrm{~min}$ VI $2 \mathrm{~m}$ in VI $3 \mathrm{~min}$ VI $4 \mathrm{~min}$ VI $5 \mathrm{~min}$. The value of the VI schedule in effect on a particular key corresponded to the number which was used to identify the key, i.e., the VI 1-min schedule was in effect on Key 1, the VI 2-min schedule on Key 2, etc. All other conditions remained identical to those previously mentioned. Ss were exposed to the five-key procedure for 80 sessions.

In addition to recording total responses and total reinforcements within a session for the individual keys, tallies were also made of the amount of time an animal spent at each key and the number of changeovers to it. Whenever a peck to one of the keys was followed by a peck to another, a changeover was recorded for the latter key. This response also initiated a cumulative timer, which continued to run until the animal switched to a different key. The timer also stopped during reinforcement. The total appearing on the timer at the end of a session was recorded as the time spent at the key.

\section{RESULTS}

Sums of the data for each $\mathrm{S}$ over the last five sessions of the five-key concurrent procedure are shown in Table 1.

Figures 1.4 depict functions derived from the data of Table 1. Figure 1 shows the relative number of responses to individual keys as a function of the relative number of reinforcements obtained on each. Linear regression lines were fitted to the data points for each bird by the method of least squares and, in general, closely approximate those predicted by the matching principle. For the situation involving choice between several concurrently available response alternatives, matching can be expressed by the equation

$$
\frac{p_{i}}{P}=\frac{r_{i}}{R}
$$

where $p_{i}$ indicates the number of responses to the particular key denoted by the value of the subscript $i, r_{i}$ represents the number of reinforcements obtained on that key, and $P$ and $R$ denote the responses and reinforcements summed over all keys. In the present case, $i=1,2,3,4,5$.

Figures 2 and 3 display the relationships obtained between the relative number of reinforcements and two other derived measures: the relative amount of time spent at a key $\left(t_{i} / T\right)$ and the relative number of changeovers to a key $\left(c_{i} / C\right)$. In both figures the points for each bird fall close to the matching line, except in the case of Bird 348 in Fig. 3. The anomalous pattern of this bird's responding will be discussed in a subsequent paragraph.

The averaged data for three Ss $(258,261$, and 299) are shown in Fig. 4.

\section{DISCUSSION}

The present experiment demonstrated the generality

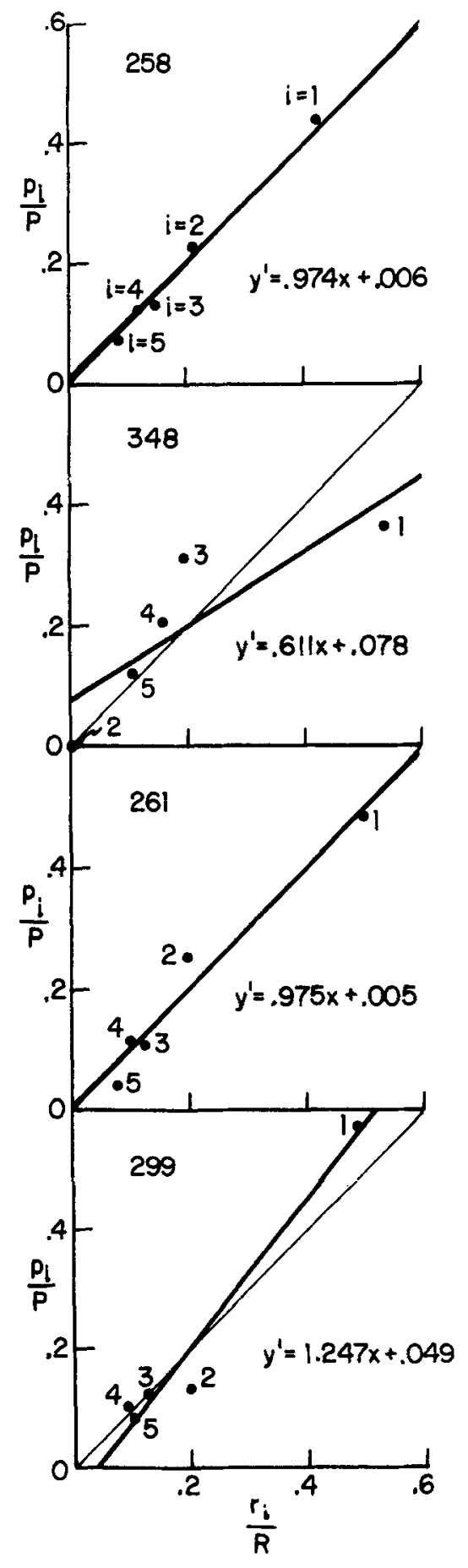

Fig. 1. The relative number of responses $\left(p_{i} / P\right)$ to each key in the five-key concurrent procedure is shown as a function of the relative number of reinforcements $\left(r_{i} / R\right)$ obtained on that key. The numbers beside the points represent the values of the subscript $i$ and correspond to individual keys. The diagonals (light lines) represent matching. The heavy lines were fitted using the method of least squares. The equations for the regression lines are shown in the lower right corner of each panel.

of the matching principle in two specific respects. It showed that when the number of alternatives is large, pigeons continue to allocate their responses in a manner 


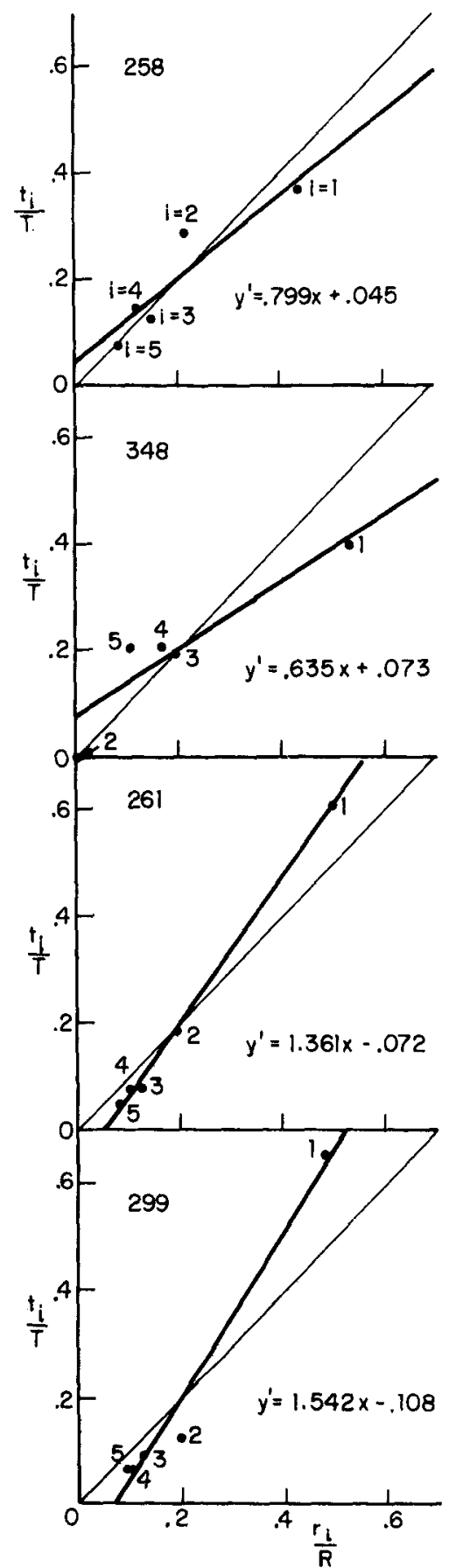

Fig. 2. The relative amount of time spent $\left(t_{i} / T\right)$ at each key in the five-key concurrent procedure is shown as a function of the relative number of reinforcements $\left(r_{\mathbf{i}} / \mathbf{R}\right)$ obtained on that key. The numbers beside the points represent the values of the subscript $i$ and correspond to individual keys. The diagonals (light lines) represent matching. The heavy lines were fitted using the method of least squares. The equations for the regression lines are shown in the lower right corner of each panel.

commensurate with the distribution of reinforcements over the existing alternatives. Beyond this, though, are the results which suggest that matching need not be narrowly viewed as the phenomenon represented by Eq. 1. In supp rt of earlier studies (e.g., Brownstein \&
Pliskoff, 1968; Baum \& Rachlin, 1969), the present results indicate that matching also occurs between the relative amount of time spent at a key and the relative

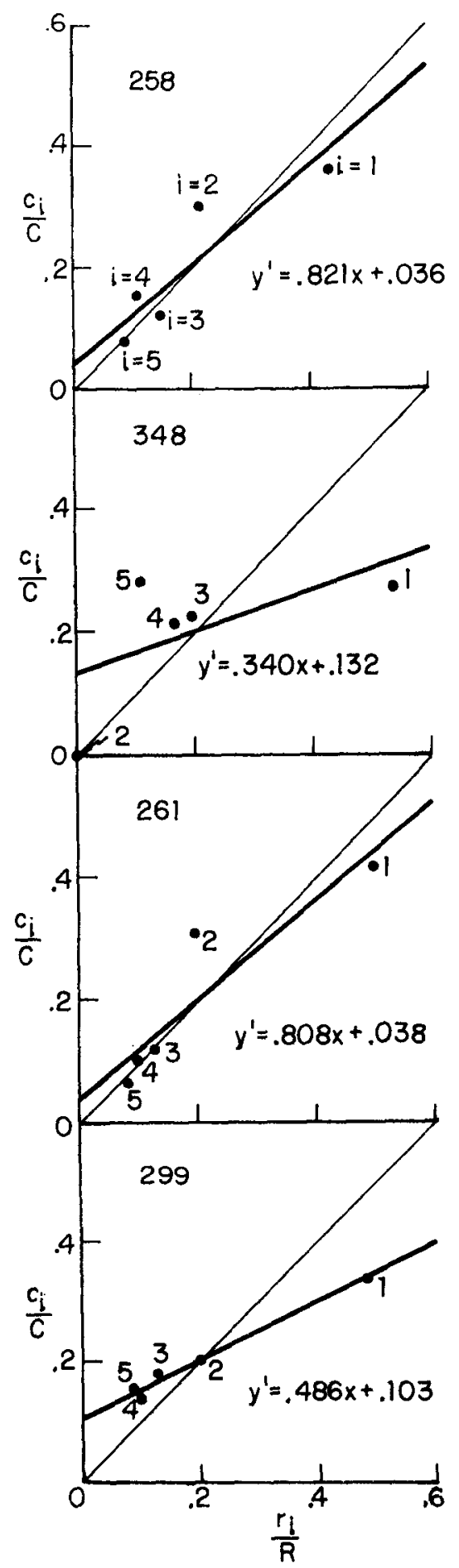

Fig. 3. The relative number of changeovers $\left(c_{i} / C\right)$ to each key in the five-key concurrent procedure is shown as a function of the relative number of reinforcements $\left(r_{i} / R\right)$ obtained on that key. The numbers beside the points represent the values of the subscript $i$ and correspond to individual keys. The diagonals (light lines) represent matching. The heavy lines were fitted using the method of least squares. The equations for the regression lines are shown in the lower right corner of each panel. 
number of reinforcements it yields. This can be expressed as

$$
\frac{t_{i}}{T}=\frac{r_{i}}{R}
$$

where $t$ is defined as the total of those intervals of time which elapse between the moment an animal switches to
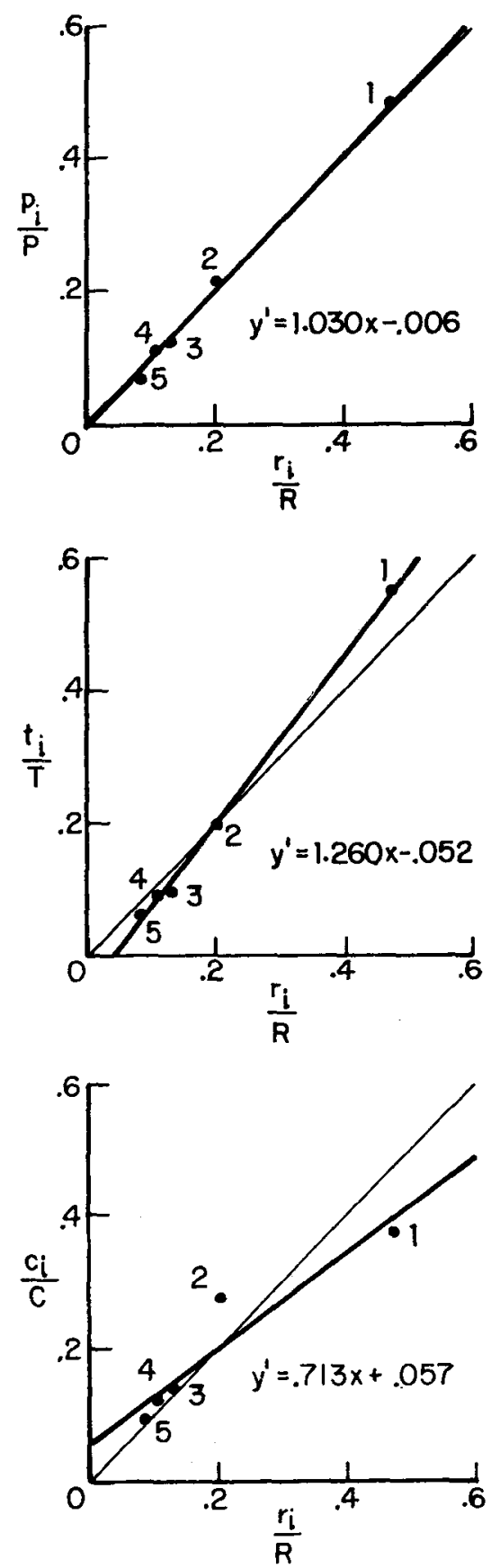

Fig. 4. Relative measures obtained from data averaged over three Ss (258, 261, and 299) in the five-key concurrent procedure. The diagonals (light lines) represent matching. The heavy lines were fitted using the method of least squares. The equations for the regression lines are shown in the lower right corner of each panel. The numbers beside the points correspond to individual keys. a key and the subsequent moment when it "leaves" it, i.e., when it switches to another key. $T$ is the sum of all such totals. The subscript $i$ and the terms $r$ and $R$ have the same definitions as in Eq. 1.

Another type of matching emerged from the changeover data and can be expressed by the equation

$$
\frac{\mathrm{c}_{i}}{\mathrm{C}}=\frac{\mathrm{r}_{\mathrm{i}}}{\mathrm{R}}
$$

where $c$ denotes the number of changeovers to a key and $\mathrm{C}$ represents the changeovers summed over all keys. $\mathrm{i}, \mathrm{r}$, and $R$ are again defined as in Eq. 1.

All four Ss exhibited matching as expressed in Eqs. 1 and 2. It is questionable whether all displayed the type of matching specified by Eq. 3. The data for Bird 348 showed the most extreme departure from matching (see Fig. 3). The behavior of this bird is noteworthy for an additional reason. Unlike the other three Ss, Bird 348 emitted very few responses to Key 2 . The reason for this is unknown. Circumstances which might have produced this result, e.g., chronic failure of the key and/or the keylight during early sessions of the five-key concurrent procedure, could be expected to have exerted similar effects on the responding of the other Ss. Such effects did not occur. Nor was the failure to peck at Key 2 observed in Bird 348 during the sessions involving that key in the two-key concurrent procedure which preceded exposure to the five-key procedure.

The paucity of studies involving choice between more than a pair of concurrently available response alternatives may be attributed to the efficacy of the two-choice method in elucidating certain functions relating behavior and the several parameters of reinforcement. The present experiment suggests that the transition from the simplicity of the two-key situation to one involving several alternatives leaves these quantitative relationships intact. In addition, it reveals a type of matching which can be exhibited only when the number of response alternatives is increased beyond two.

\section{REFERENCES}

Autor, S. M. The strength of conditioned reinforcers as a function of frequency and probability of reinforcement. In $D$. Hendry (Ed.), Conditioned reinforcement. Homewood, Ill: Dorsey, 1969. Pp. 127-162.

Baum, W. M., \& Rachlin, H. Choice as time allocation. Journal of the Experim ental Analysis of Behavior, 1969, 12, 861-874.

Brownstein, A. J., \& Plisk off, S. S. Some effects of relative reinforcement rate and changeover delay in response-independent concurrent schedules of reinforcement. Journal of the Experimental Analysis of Behavior, 1968, 11, 683-688.

Herrnstein, R. J. On the law of effect. Journal of the Experim ental Analy sis of Behavior, 1970, 13, 243-266.

Reynolds, G. S. On some determinants of choice in pigeons. Journal of the Experimental Analysis of Behavior, 1963,6, $\mathbf{5 3 - 5 9}$.

(Received for publication October 26, 1973; revision received December 26,1973 .) 